Article

\title{
Landscape Analysis and Urban Description of Bethlehem Historical Center: A Methodological Approach for Digital Documentation
}

\author{
Francesca Picchio and Raffaella De Marco* \\ DICAr Department of Civil Engineering and Architecture, University of Pavia, 27100 Pavia, Italy; \\ francesca.picchio@unipv.it \\ * Correspondence: raffaella.demarco@unipv.it
}

Received: 2 January 2019; Accepted: 29 January 2019; Published: 2 February 2019

\begin{abstract}
Bethlehem's territory and the architectural heritage present in its historical city center result from the stratification of different cultural activities, religions, and urban policies that have conditioned the actual image of the urban landscape. The city, apparently conformed as a single urban entity, is structured on multiple apparatuses of complexity, and the application of principles of decomposition and cataloging becomes a fundamental method for the analysis of the built system. To better understand the relationship between the original settlement and the historical quarters of the city, and to define a tool for their conservation and development, the present research project, developed since 2018 in synergy with administrations and local authorities, and scientifically coordinated by the University of Pavia, Department of Civil Engineering and Architecture, seeks to promote a documentation protocol that, starting from a report analysis on landscape and urban context, methodologically defines the development of an integrated digital database, constituted by multiple informative layers, to ensure better management of the city. This contribution illustrates the first step of the survey activities, which represent a preparatory phase for the organization of the digital acquisition campaign, to highlight the structure of current urban development, the divisions in neighborhoods, and the understanding of architectural values, to give guidelines for the enhancement of historical and traditional values of architectural heritage.
\end{abstract}

Keywords: architectural survey; environmental analysis; urban conurbations; Bethlehem

\section{Analysis of Bethlehem's Urban and Landscape Evolution}

The territory surrounding the city of Bethlehem is located in a part of land between the Mediterranean Sea to the West, the Lebanese valley to the East, the Hermon to the North, and the Negev desert to the south. The territorial boundaries of this area have never had a specific definition, nor have the people that have succeeded over time.

The same city of Bethlehem, which rises a few miles south of Jerusalem in the area called the West Bank, has seen a succession of people from the land of Canaan, Arabs and Jews, Romans (132-135), people from the Islamic caliphate, Crusaders, Ayyubids, Mamluks, Greeks (Orthodox), and Armenians, who, with their work and their domination over the centuries, have led to important transformations up to the current urban conformation [1]. The construction and related events of what today is considered the most important building of the city have conditioned the urban transformation of the historical center (Figure 1). 


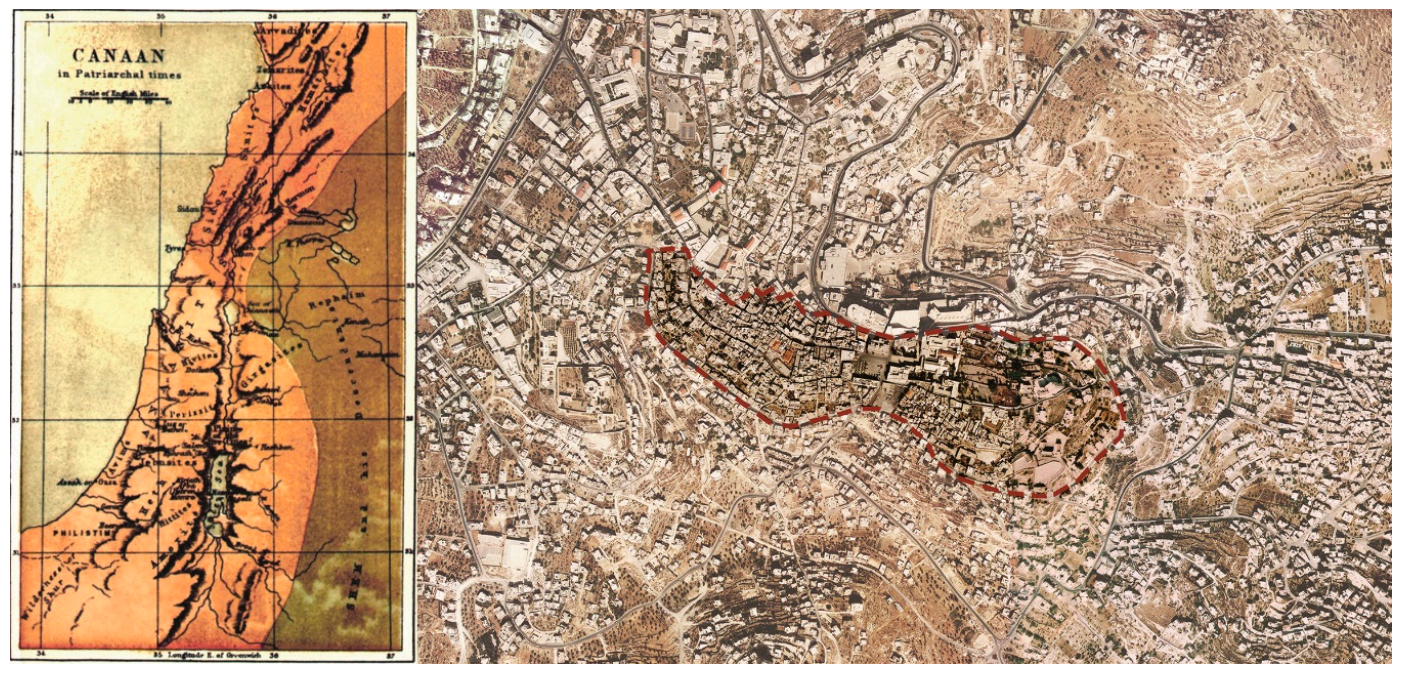

Figure 1. Map of Canaan in patriarchal times. Map of Bethlehem in 1880, showing Bethlehem's environmental context and historical city center.

The complex of the Nativity Church, which rises above the cave venerated by the earliest Christians as the birthplace of Jesus Christ, was built in 326, commissioned by Constantine after his proclamation of freedom of worship, and subsequently modified by Justinian in 540 . The attack of 614 by the Persian army of Cosroe, who spared the basilica, saw the total destruction of the city. The city was partially rebuilt by Arabs until the crusader conquest of 1099. The entire territory of Palestine, including the city of Bethlehem, was occupied by Salah e-Din in 1187 until the return of Christians in 1192. From that moment until the nineteenth century, the city suffered an unstoppable decline that reduced Bethlehem to a poor village with a few hundred inhabitants. The increase in the Christian population led to a progressive rebirth of the urban center, but at the same time caused a growth of clashes with the Muslim population, until the destruction of the Muslim quarter in 1834 . Conquered for the Turks by the British in 1918, the city followed the fate of the West Bank. Situated in the area under Israeli military administration following the June 1967 war, Bethlehem has been under Palestinian jurisdiction (the Palestinian National Authority) since 1995.

The definitions of these historical phases, and of these events that have influenced the urban development of Bethlehem city center, are fundamental for analyzing, understanding, and documenting the formal aspects of the area.

The architectural heritage present in the historical city, defined by the presence of different populations, cultures, religions, and urban policies, highlights an overlap of systems and constructive units also found in the use of materials and in the reuse of technological and decorative components, which identify the transformations of buildings and the history of settlements (Figure 2).

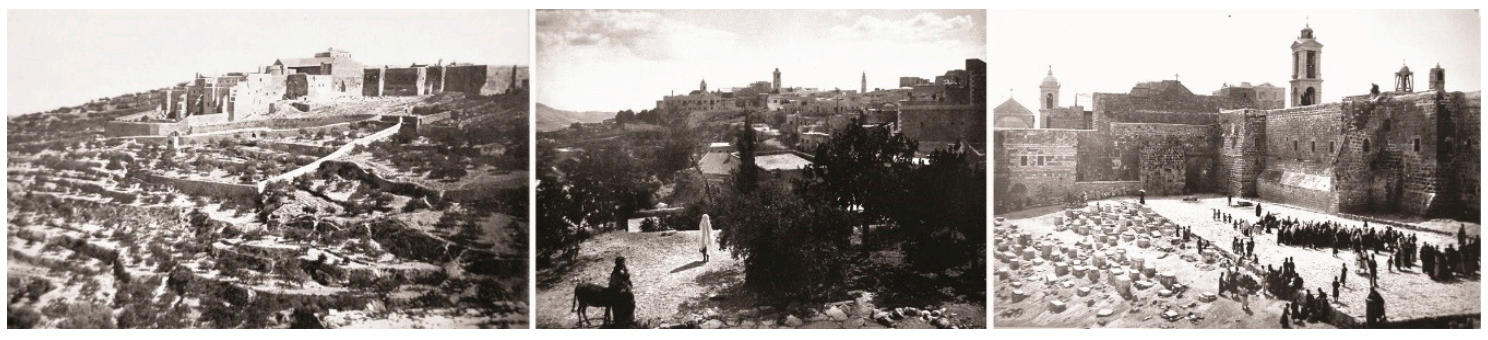

Figure 2. Historical images of the rural context of Bethlehem (first and second) and the transformation of space around the Nativity Church at the beginning of the 20th century (third image).

The need to create tools for the documentation and analysis of the city's historical image [2], which can help administrations manage the city and develop new construction policies, becomes even 
more important in a deformed landscape like the Bethlehem city center: oppressive policies lead to the loss of symbolic, social, and cultural values, which are complicit in a distorted perception of the original city image [3] (Figure 3).
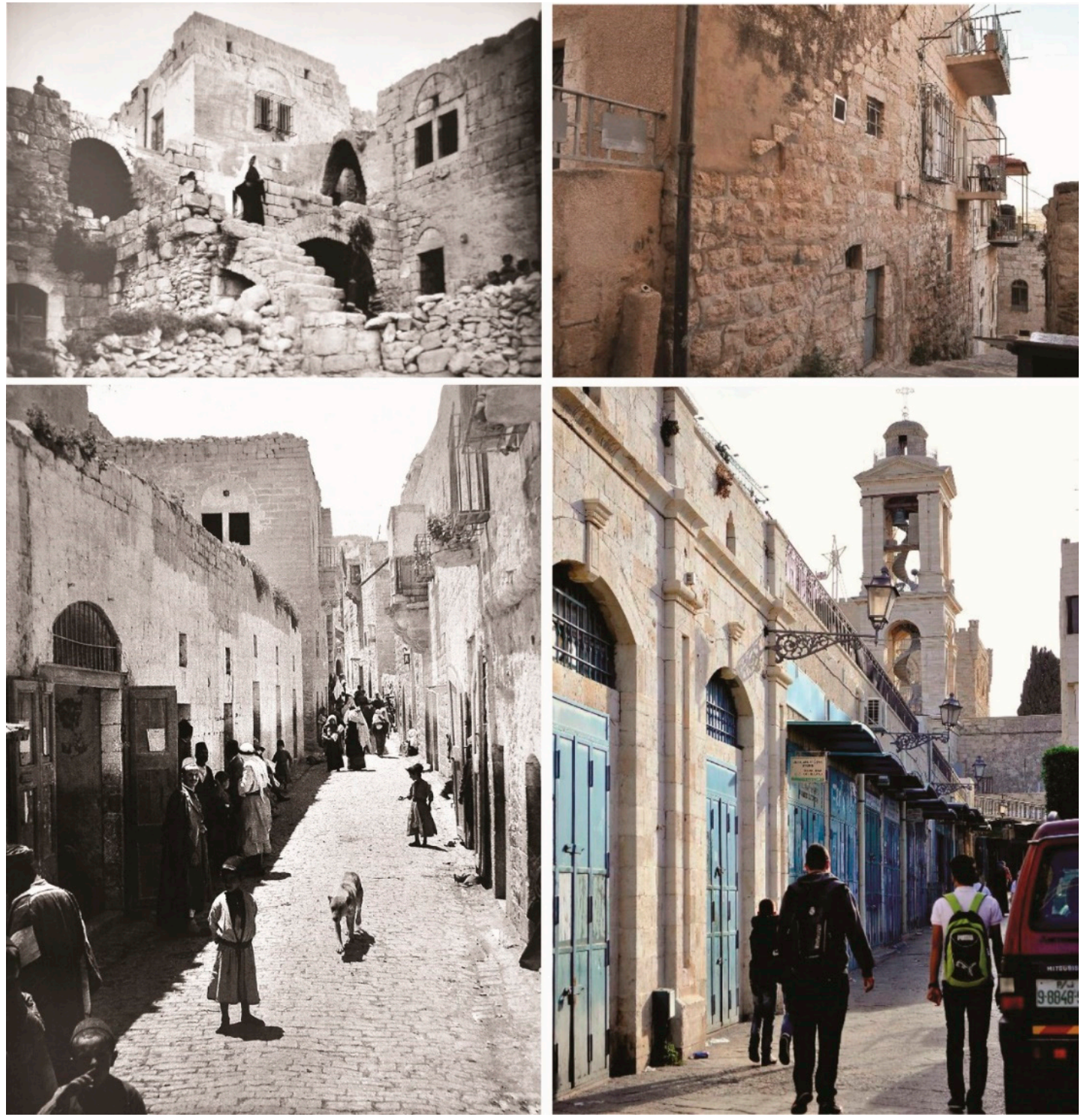

Figure 3. Examples of Crusade features in the historical center of Bethlehem:an historical rural building belonging to a cluster (up), below, a view of the historical Milky Way (down).

In this context, the saturation of the urban fabric with new constructions, aggregates, and external blocks generates architectures of low value, without any type of structural, technological, or environmental control by administrations, sometimes with dangerous structural risks, in addition to obvious formal discrepancies with respect to the building typologies and materials of historic buildings.

With the aim of documenting the current status of the historic city center of Bethlehem, survey campaigns have been conducted since 2014 .

After the project research for the documentation of Nativity Church and the surrounding streets [4], documentation activities have been carried out in the historical city center to develop a documentation system that, thanks to the output of digital survey data acquisition, could generate a three-dimensional database of the urban environment, which could be used to extract information useful for understanding the space configuration and structuring a management plan of the territory. 
This purpose of this is development as part of the international cooperation project, "Management and Control of Urban Growth for the Development of Heritage and the Improvement of Life in the City of Bethlehem". During the next three years (2018-2021), this project will implement a technological process of the analysis of the urban form in order to plan the future city. The project, scientifically coordinated by University of Pavia, in an international partnership guided by the Municipality of Pavia and financed with the contribution of AICS (Italian Agency for Cooperation and Development), and supported with enhanced contribution from project partners, aims to give a foundation for improving the territorial governance of the Municipality of Bethlehem and the control of the city's growth.

The preliminary activities of the first survey campaign have tried to highlight the structure of current urban development, divided by neighborhoods concentrically located around Manger Square (al-Najajreh, al-Farahieh, al-Anatreh, al-Tarajmeh, al-Qawawseh, Hreizat, and al-Fawagreh), to analyse the image perceived by the population and visitors, and to give guidelines for the development of historical and traditional values of architectural heritage, as well as an infrastructural increase of services, buildings, and activities (Figure 4).

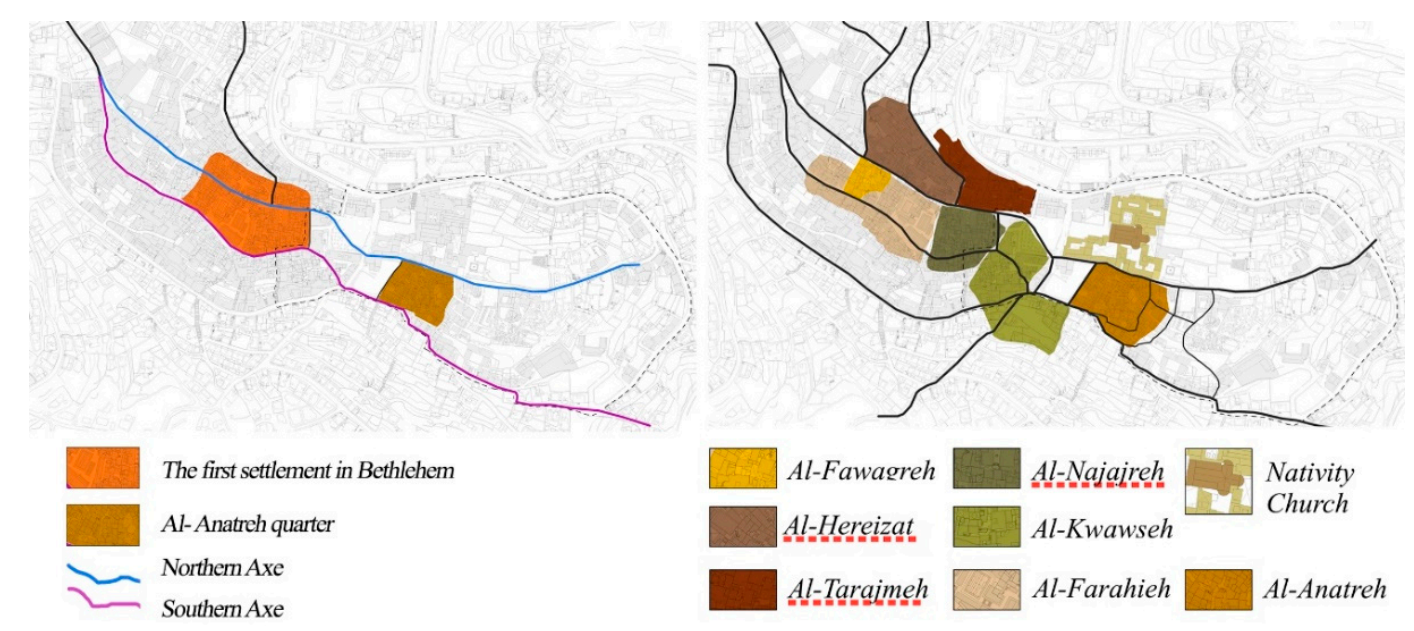

Figure 4. Bethlehem origins from the concept studies of Revault, Santarelli, and Weil-Rochant. Blue: Northern Axis; purple: Southern Axis; on the right, the division in quarters at the end of 19th century.

\section{The Development of Historical Districts: Subdivision of the City Center and Urban Levels Classifications}

To manage the complexity of the irregular urban landscape and its architectural aggregates, the first analysis focused on the subdivision of the historic center of Bethlehem into different areas of interest. The first subdivision, programmed on the basis of the main driveway roads, describes a network arranged in concentric rings. The driveways' paths follow an irregular ridge in which a portion of the city center is spread, defining portions of cities arranged on various altimetric sectors.

Subsequently, each area was further subdivided into fabric units, consisting of blocks or clusters defined by continuous masonry portions, as structurally integral portions, and delimited perimetrically by pedestrian accesses, stairways, or small open spaces constituting urban vacuums. The clusters are constituted by different building units, which have been appropriately analyzed and classified individually, representing the smallest architectural entity of the research analysis.

Due to the complexity of fabric agglomerations and the difficult interpretation of the tissue unit of some aggregates, the division into areas and blocks was supported by existing historical documentation and the municipality cartographic census.

The analysis of the historical evolution of Bethlehem showed that the first settlement, surrounded by a perimetrical wall, maintained its configuration on the top of the ridge until the 19th century, when it begun to expand towards the north and west sides. The 20th century's city growth concerned 
uncontrolled development of the urban fabric in a gradually but non-geometric organic form that followed the geomorphic ridge rather than a specific grid pattern [5].

One of the most interesting portions of territory for research purposes is the southern part of the city next to the complex of the Nativity Church, situated on the same ground level of the ridge. The density and complexity of the building aggregates of the Anatreh Quarter configured it as the perfect case study on which to test the activity goals of digital documentation and analysis of the urban landscape, in order to produce a repeatable methodological protocol on the whole historical center and also on other urban contexts of the Middle East [6].

The district, likely included within the perimeter of the Roman city walls, was probably developed for the most part during the Byzantine period, and it was probably the place of multiple religious orders during the Crusader period.

Based on these historical synthesis and geomorphic aspects, recent studies have hypothesized that the south part of Bethlehem city center could be divided in four main development phases: Two main east/west axes in the 16th century, the east urban expansion in 19th century, a further expansion towards the east until the emergence of Catholic and the Greek Orthodox churches at the beginning of the 20th century, and finally the extension towards the Qawawseh Quarter during the British Mandate (Figure 5).
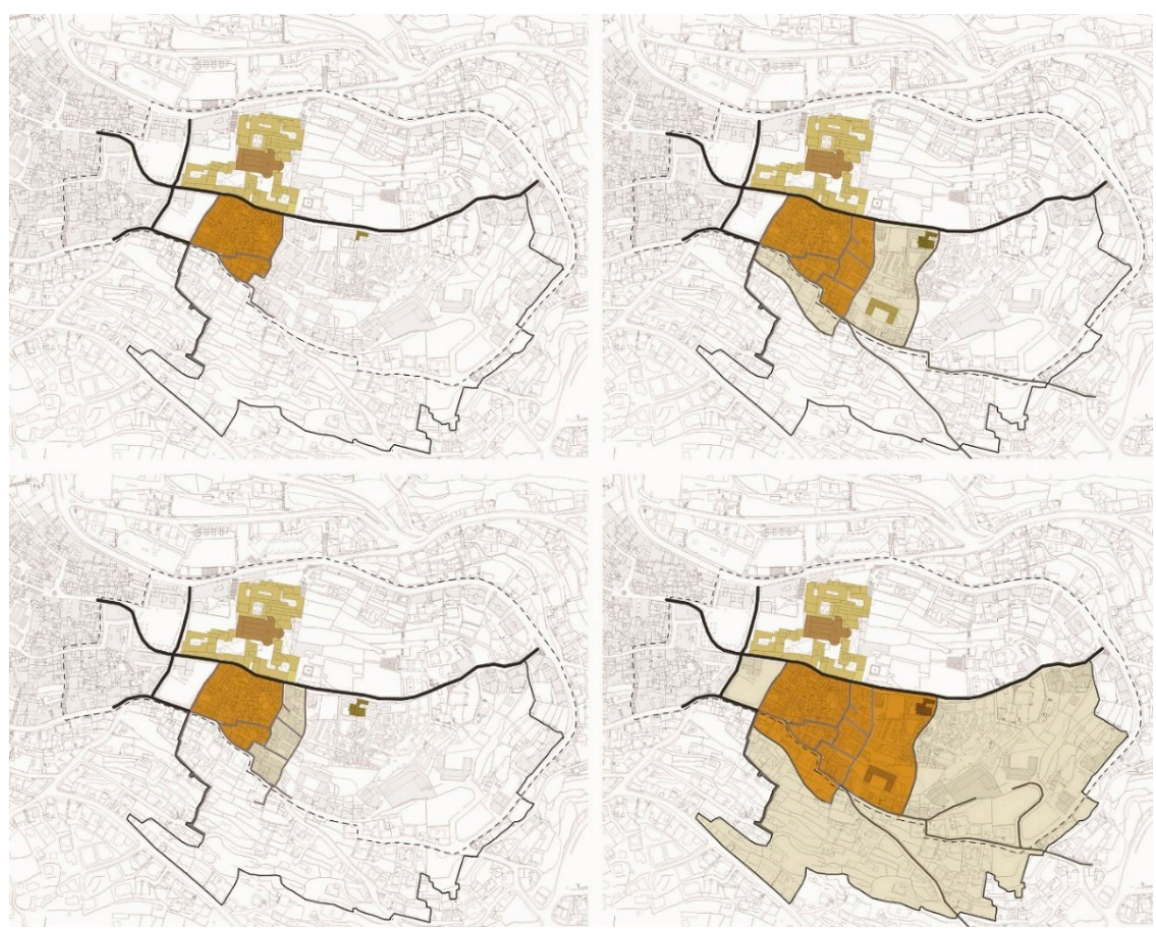

Figure 5. Urban development of Anatreh Quarter in different centuries. From the top on the left: Beginning of 16th century, beginning of 19th century, beginning of 20th century, and today.

The urban development of this part of the city is due to different geological, religious, and political aspects: the Anatreh Quarter has been destroyed and rebuilt many times during the centuries, and what appears today belongs, for the most part, to the Ottoman period. Moreover, urbanization and building development are due to a policy of improvement of services for the Christian population mandated by foreign missionary programs (such as the British Ladies' Mission) and the mass return of many Bethlehemities from European contexts and cultural influences, which have given the buildings of the district decorative elements and modern amenities, making the image of the quarter stylistically different and recognizable as unique in the Bethlehem urban landscape. 
The subsequent phenomenon of abandonment due to the restrictive Israeli policies of 1993 and the incursion of 2000-2002 caused the progressive damage of many structures, which led to a restoration program a few years later.

With regards to housing, the Anatreh district is physically divided into several ahwash, called clusters, that represent urban complexes, occupied by families and their extended kin. On the other side, the landscape image is characterized by the presence of larger scale individual buildings and field houses, which are perfectly balanced and integrated into the building, mostly with residential functions, and are arranged asymmetrically, with the fronts facing the inner courtyard and the backs on the narrow pedestrian path that connects the various aggregates, gradually decreasing in density towards the south and east directions. The structures are built from characteristic Jerusalem stones, which give a homogeneous organic aspect to the city, emphasizing the geometric volumes of the building blocks (Figure 6).

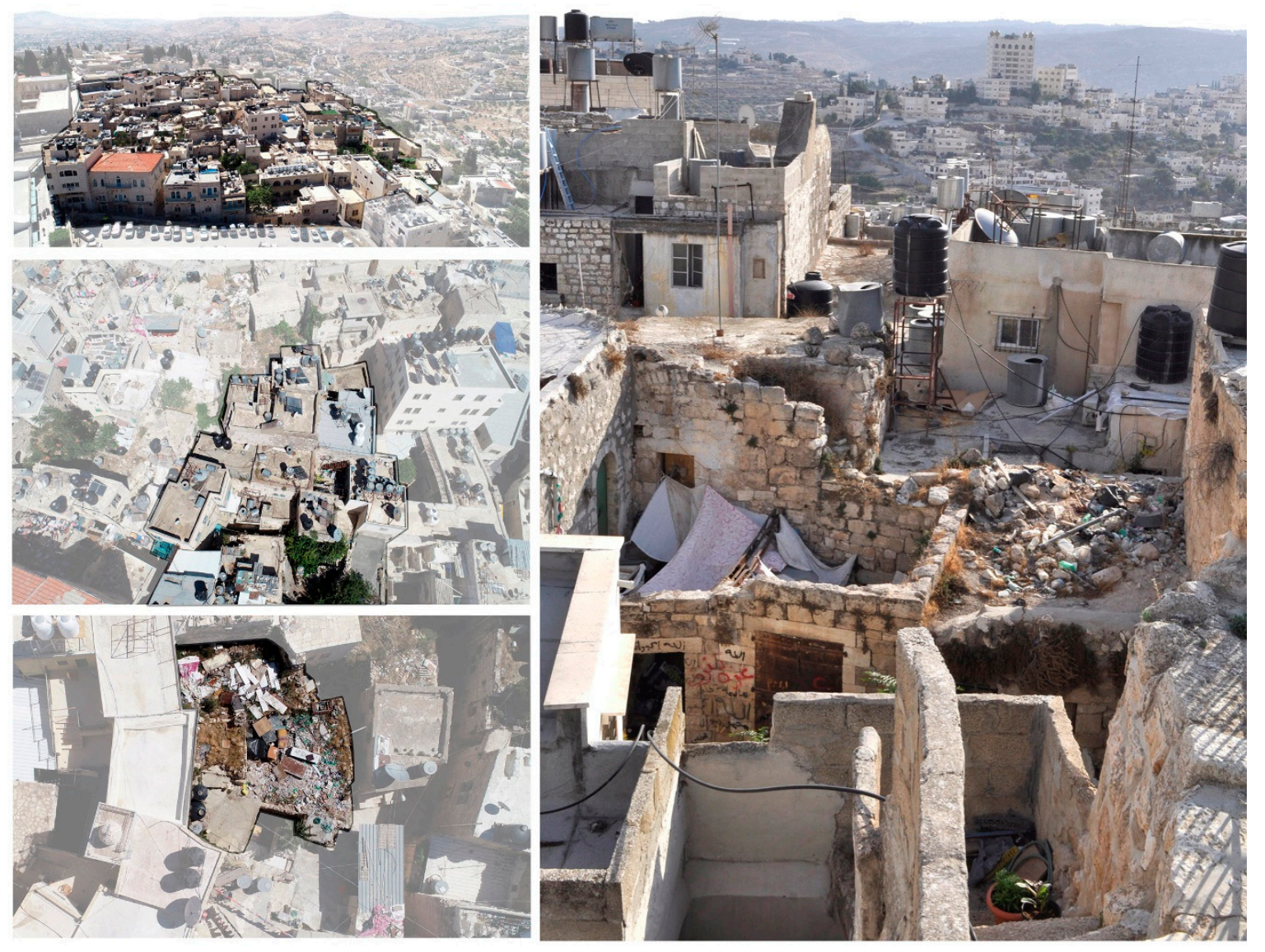

Figure 6. An image of the urban complexity of the city center from the roofs and subdivision process of the Anatreh Quarter. From the top on the left: areas, clusters, and building units.

\section{The Building Characterization of Districts: Ahwash Structure and Constructive Types}

The macro division into aggregate units, as a result of the deepened decomposition of the complexity of the urban historical area, still represents an intermediate level-the architectural one-in the classification of the constitutive realities of the built heritage of the city of Bethlehem. The architectural unity of the hosh (pl. awhash), the urban district, identified as the organic structure of the family nucleus before being formally conceived as a building entity, introduces a system of organizing the urban planimetry based on a dense agglomerate, which is constituted itself by building units of several types and variations recovered together in a harmonious and compact mass (Figure 7), where remarkable architectural complexes and constructive characters emerge inside as unique traditional examples [7]. 

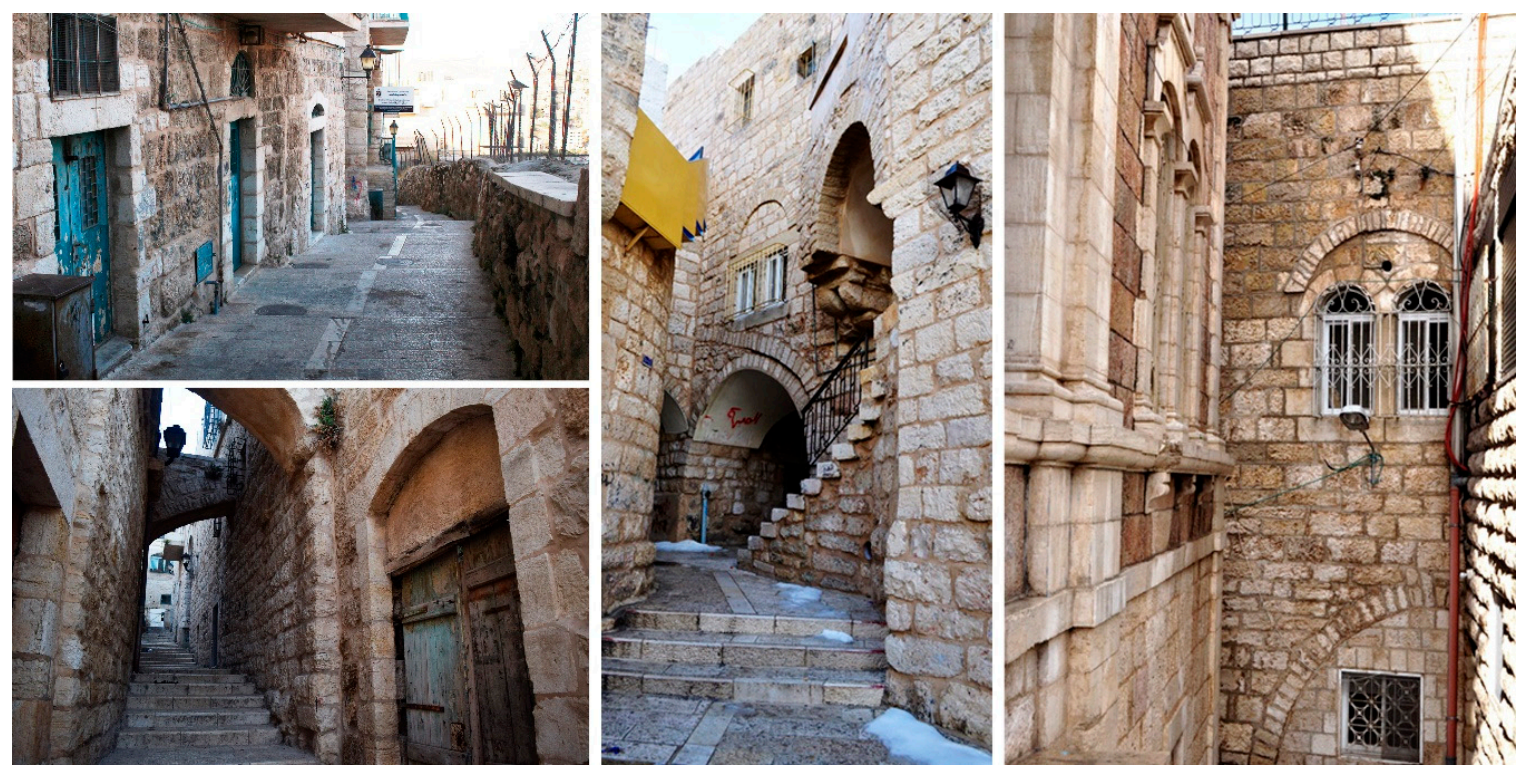

Figure 7. Urban morphology of awhash and internal stairways in Bethlehem historical center.

The decomposition into building units of the ahwash, tested in the first phase of investigation on the districts of Al-Anatreh and Al-Qawawseh, led to a dual organizing principle at the base of the development of the settlement areas from their Constantinian origins until the 19th century. This phenomenon is observable in the entire historical center of Bethlehem. From a landscape consideration, the settlement phenomenon, developed with stable affirmation by local nomadic tribes, has manifested in the territory through a spirit of adaptation and habitual attitude contextualized in a landscape with strong morphological connotations of the territory. The structure of the city of Bethlehem, centered around one of the major mounts of the Jerusalem valley before the geological depression of the Dead Sea, has conditioned urban planning by obliging the city to adapt its agglomerations to the natural difference in ground-level (approximately 40 meters), conforming architectural environments and urban routes to arrange along the slopes, with constructive levels, terraces, and descending stairways declining from the monumental nucleus of the Nativity Church on the top.

Regarding the social and urban aspect, remnants of the traditional living of the clans that founded the city, who also established the basis of its social and economic structure, directed the typology of architecture of the ahwash. This patriarchal influence has been translated into the form of constructive and distributive features of architectural environments, exemplified in the relationship between private spaces, artcraft workshops, and warehouses, where private life derives its organizing and characterizing principles from integration with historical local production activities, such as olive harvesting and crushing, oil production and conservation, and olive wood and mother-of-pearl craftsmanship. The same organization of the residential premises, located on the upper floors with internal labyrinthine arrangements, maintained concentrically to the internal courts, is often not limited to the volumetric bodies visible from the outside but presents constructive solutions for connections by using architectural diaphragms, cross vaulted passageways (qantara), and up-level junctions between units and many times between ahwash (Figure 8). 

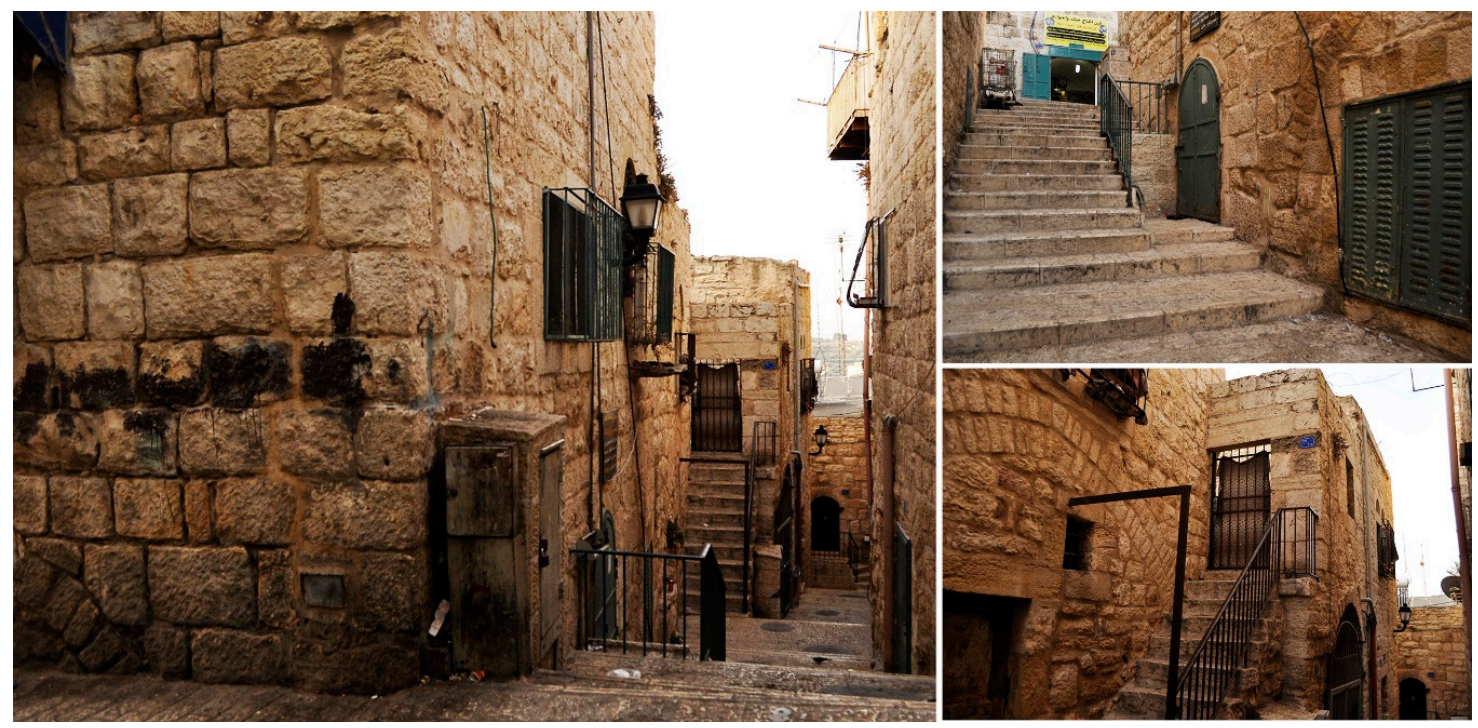

Figure 8. Morphological conformation of the district of Al-Qawawseh district: the slope of the territory has been architecturally designed over the centuries, with building solutions organized into multiple levels (underground and raised), and accesses realized through urban stairways and unit staircases.

The organization of building units within the agglomerations of the awhash has been structured following the conformation of public space and the external urban routes, which then develop in their internal complexity with different and unique solutions. Residential units are laid out frontally in an asymmetrical planification, following the polygonal direction of the internal roads. The hosh tends to close on itself, refusing to relate the interior spaces with the urban environment, protecting them from the impact of winds, storms, sun, noise, and intrusion of waste from streets. The main view is on the inner courts, which are always classified as private spaces, inside which constructive solutions of balconies, terraces, and vaulted porticoes are common. At the center of the typical settlement of the historical center of Bethlehem, the delimited interior space is central-unlike the open space of the urban context-and external and foreign to both the unit and the protection of the clan. For the same reason, openings of main fronts on urban routes are reduced, limited to the necessary entrances for courtyards, small gate doors obtained in the perimeter walls, or for spaces of production and sale activities, while the windows of residential buildings are concentrated in the upper levels to ensure greater privacy from the street level of public life, following the Ottoman building code [6].

At the volumetric level, residential units are constituted by the repetition of around five cubic metre modules around a central space (the courtyard) from which they are accessible through private doorways or stairways to the upper built levels. Primary structures, constituted of masonry wall in local Jerusalem stone, are located parallel to stairways as original hosh borders, while additional modules, both in historical stone or more recently in prefabricated cement and metal components, haphazardly fill the intermediate and resulting spaces, sub-dividing courts with partition walls and units of extra-structure, losing their original shape and function. A network of private passages and openings interconnects one or more of the entrances to each hosh. This network also starts from the inner courts, where spaces and apparatuses for semi-public activities are located as original common spaces for the clan life (Figure 9).

The internal distribution of architectural premises is organized on several levels, following the natural difference in level of the ground, with underground environments attributable to the original caves of the first settlements, adapted to stables and warehouses, and higher levels dedicated to living quarters. Structurally, environments are mainly defined by box-shaped compartments in load-bearing masonry, covered by barrel vaulted systems, cruising, or by Ottoman domes raised to the level of roofs to guarantee rain discharge. Successive intervents and addictions, such as adding concrete walls, changing building levels and roofs, subdividing units, and interfering with the morphology of the 
hosh, have often altered the proportions of original structures. The random evolution of ahwash blocks is also reflected in their facades, with a wide variety of asymmetrical openings (Figure 10), and signs of historical changes in architectural adaptive reuse [6].
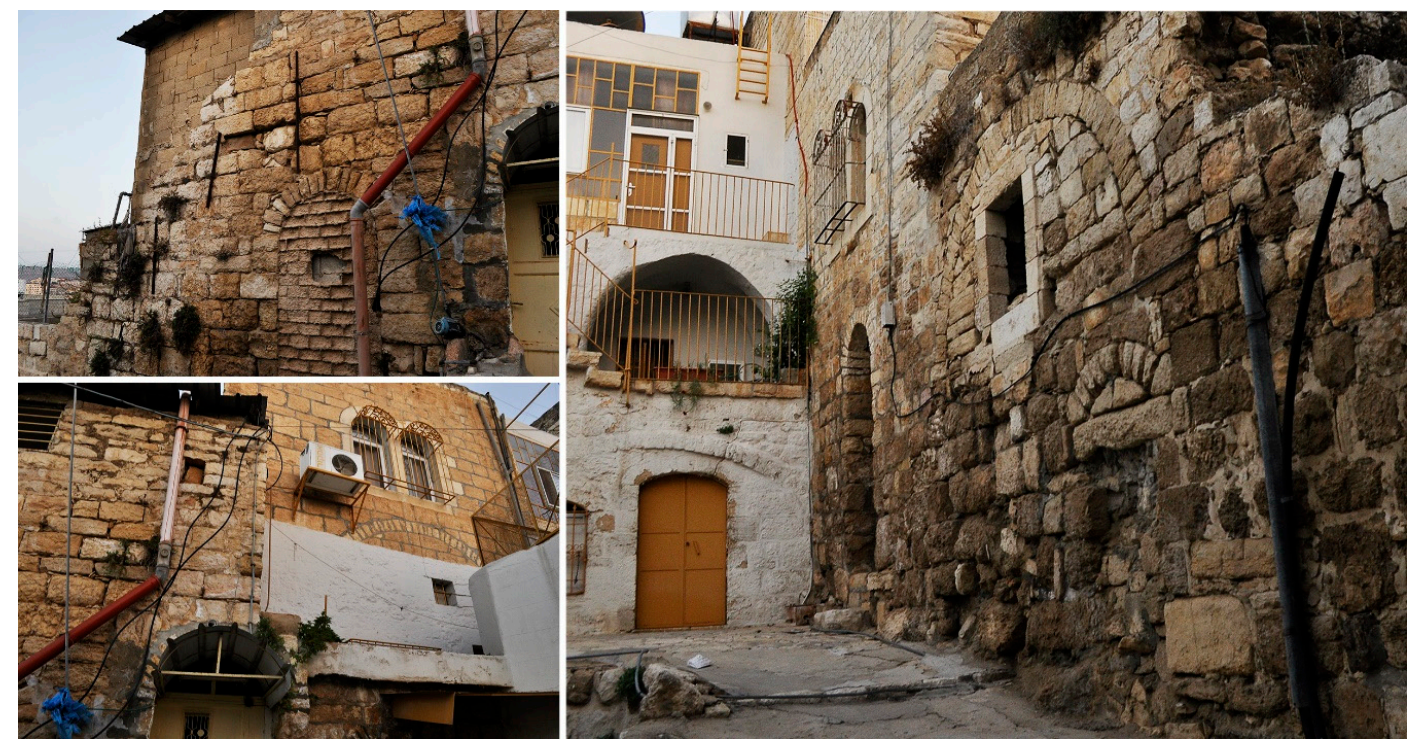

Figure 9. Structural adaptions and interventions in the conformations of building aggregates and awash.
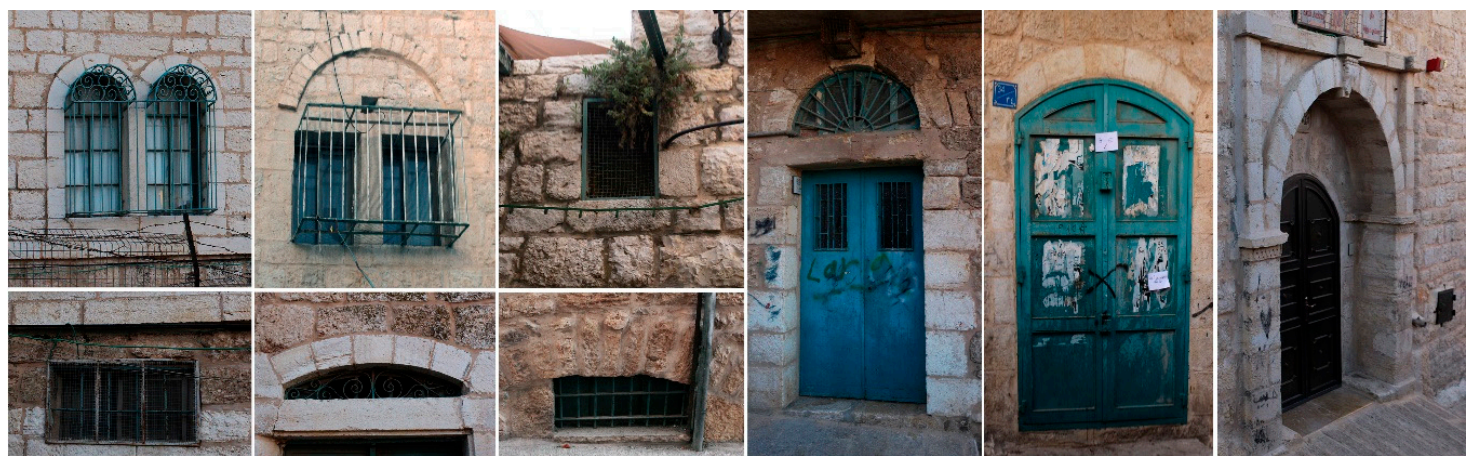

Figure 10. Constructive elements and opening solutions, original or from subsequent interventions.

\section{Preliminary Considerations for Digital Survey: Instruments, Methods, and Databases}

The extreme urban, architectural, and construction variety found in the territory of Bethlehem has occasioned an action of documentation of the historical center oriented toward a double target of investigation. At the territorial scale, the request addresses the complexity of the urban plan, from the dense urban aggregates to the expansion areas, in order to document the anthropic complexity of the built landscape for the evaluation of urban facilities and services for administrative governance. At the architectural scale, the uncontrolled evolution of building saturation and masonry morphologies has urgently led to the monitoring of possible risk factors linked to constructive configurations of the historical city, modified and hybridized between original paraments and modern inserts in structural solutions of altered static behaviour between both building blocks and aggregates (Figure 11). 


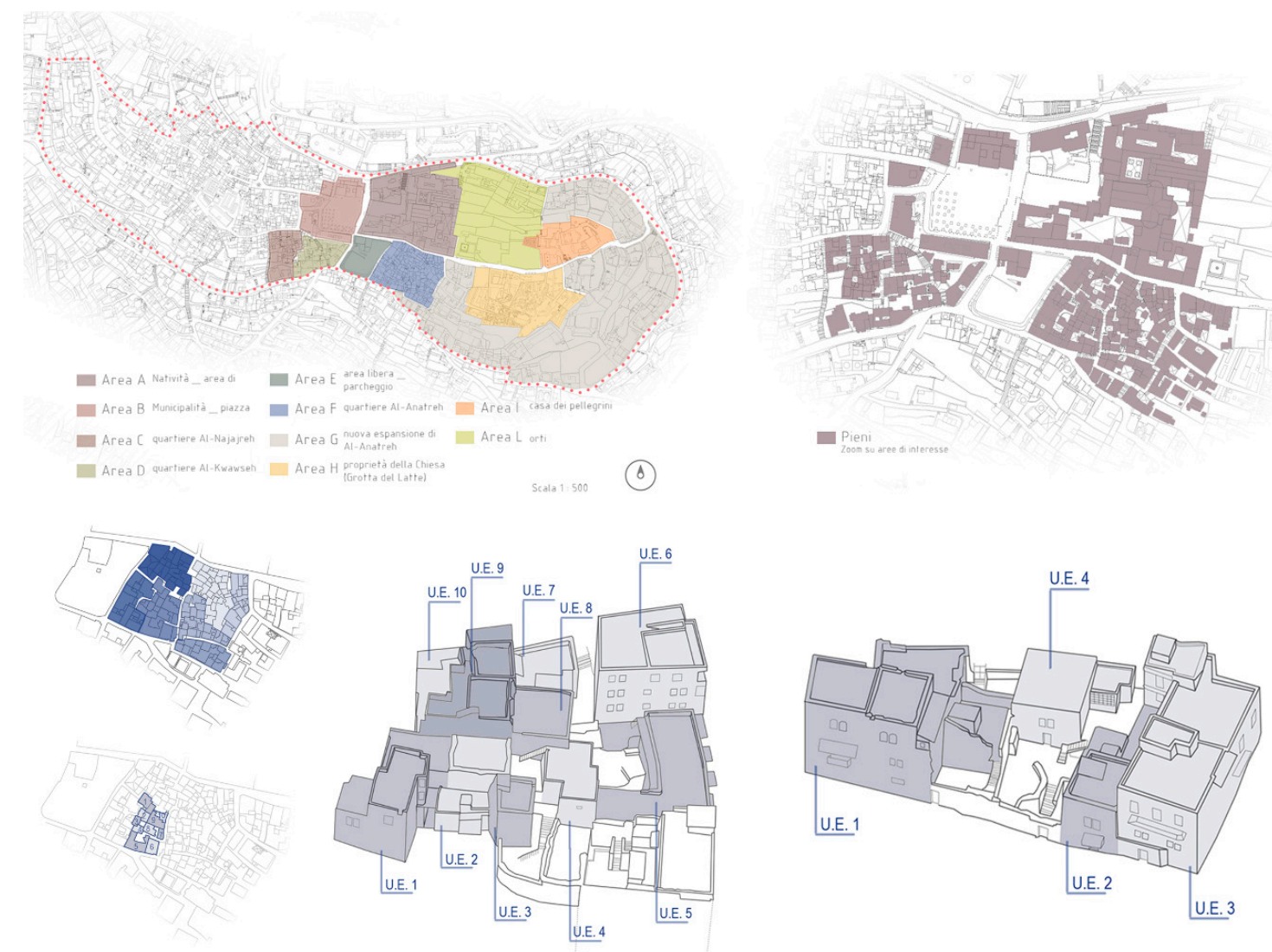

Figure 11. Subdivision criteria developed during the first campaign of documentation (July 2018) in the Bethlehem historical center, tested in the classification of aggregate units and building units in the area of the Al-Anatreh district.

Thus, the research is focused on the application of digital methodologies for the acquisition and representation of the city [8], in order to structure a multi-scale and multi-range survey action. The virtual transposition of Bethlehem's urban structure, digitized in a 3D database of metric reliability, is intended to describe and simplify the complexity of district buildings, semantically organizing the virtual space to guide the consultation and extraction of referenced information. In this way, the identification of each building unit becomes a simplification tool for the reading of the original drawing and stratification of the historical city, where the decomposition of urban levels, according to descriptive keys, directs both the process of analysis and synthesis [9].

Starting from the south-east area surrounding the monumental site of Nativity Church (already examined by a project of documentation in 2015), a documentation campaign started in 2018, analyzing the extensive application of different instruments of acquisition to integrate multiple but complementary digital outputs.

By planning an accurate decomposition of architectural surfaces to guarantee, through common connection and registration portions, the global coverage of documentation for built areas, the preliminary morphological analysis of the building context has proved to be fundamental in the distinction of the range and acquisition capacities of individual instruments (Figure 12).

The survey was conducted with the use of a static Terrestrial Lidar, and aerial photogrammetric acquisition by drone, ensuring a total coverage of the urban center conducted at multiple levels of observation and stratification of the built system. 


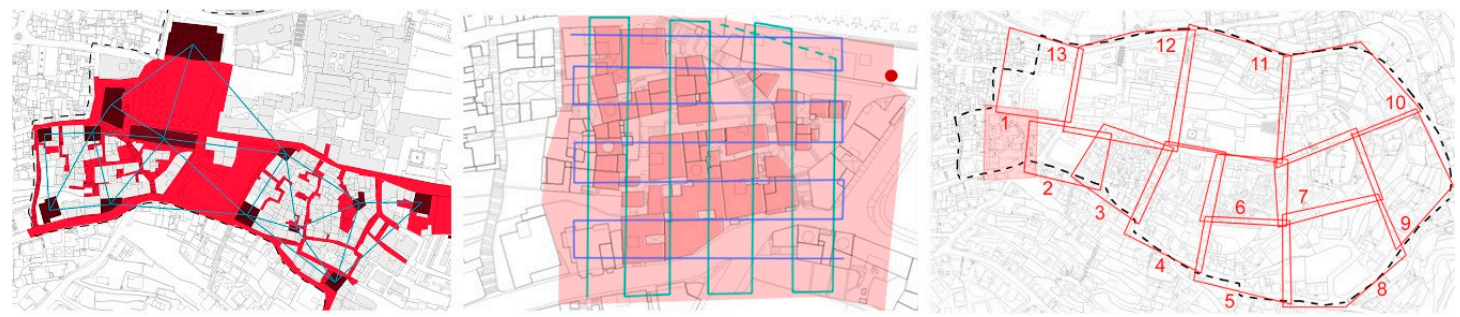

Figure 12. Project approaches for spatial control in survey campaigns, tested on the Al-Anatreh district, with a Terrestrial Laser Scanner (data acquired from streets, stairways, and keypoints of coverage level), aerial photogrammetry by drone (with grid plans of acquisition trajectory for the drone flight), and close-range photogrammetry (acquired from the ground level while considering the surface organization of aggregate and building units).

Laser scanners were used to acquire a large amount of data at even greater distances, with scan stations distributed along urban routes and from the top of selected buildings chosen for their position and height, which also ensured target points for the georeferencing of aerial data. At the same time, the photogrammetric campaign by drones followed the logic of acquisition of large scale data, using the streets as elements of subdivision of the areas, but necessarily confronting the constraints given by the conformation of the space: the density of buildings, differences in the height of city areas, and the presence of vertical elements (trees, bell-towers, and minarets) [10].

\section{Conclusions}

The effective necessity of an instrument of documentation for the historical center of Bethlehem, for the control and management of urban and territorial complexity and of built morphology, emerges from explicit calls for intervention by local and institutional authorities. The development of a digital database, based on reliable metric and census data on architectural aggregates and urban context, is central to starting a renewed administrative process for elaborating archival methodologies, documentation systems, and operational protocols to respect of the city and its heritage. On this basis, the international cooperation project "Management and Control of Urban Growth for the Development of Heritage and Improvement of Life in the City of Bethlehem" has been founded, with the aim of promoting the strengthening of territorial governance of the Municipality of Bethlehem.

This research project (2018-2021) is oriented towards the development of programs to safeguard the active control of both the historical center and development areas, as well as monitoring factors of risk and values of sustainability for the enhancement of cultural character and the renewal of the city [11].

\section{Patents}

Author Contributions: The editorial responsibility of the paragraphs was given to the following people: F.P., for the abstract and paragraphs 1 and 2; and R.D.M., for paragraphs 3 and 4, and conclusions. Conceptualization, F.P. and Raffaella De Marco; Writing: original draft, F.P. and R.D.M.

Funding: The project "Management and Control of Urban Growth for the Development of Heritage and Improvement of Life in the City of Bethlehem" was financed by a ministerial grant from the AICS Italian Agency for Cooperation and Development. It was coordinated by the Municipality of Pavia, with a partnership composed of the Municipality of Bethlehem, the University of Pavia (scientific coordination), the University of Bethlehem, the Province of Pavia, the Order of Engineers of Province of Pavia, the SISTERR Territorial System of Pavia for International Cooperation A.P.S., ANCI Lombardia, the VIS-International Voluntary Service for Development NGO, and the Palestinian Engineers Association, Jerusalem Center. The project was scientifically coordinated by Prof. Sandro Parrinello, director of the DAda Laboratory of DICAr, the Department of Civil Engineering and Architecture of University of Pavia; part of the project was developed within the master's degree thesis of stud. Paola Barazzoni in Building Engineering and Architecture at the University of Pavia, during DAda Lab research activities.

Conflicts of Interest: The authors declare no conflict of interest. 


\section{References}

1. Ring, T.; Schellinger, P.; Watson, N. International Dictionary of Historic Places: Vol. 4, Middle East and Africa; Fitzroy Dearborn: London, UK, 1996.

2. Parrinello, S.; Picchio, F.; De Marco, R. Il paesaggio ed il colore del Medio Oriente: Sistemi di rappresentazione ed analisi tra passato, presente e futuro. In Colore e Colorimetria-Contributi multidisciplinari, vol. XIIA, Proceedings of the 12th Conferenza del Colore, Turin, Italy, 8-9 September 2016; Macchiafava, V., Ed.; Gruppo del Colore: Turin, Italy, 2016; pp. 49-60.

3. Cohen, A. Palestine in the 18th Century; Varda Books: Jerusalem, Israel, 2009.

4. Becherini, P. La Basílica de la Natividad. Experiencias significativas integradas a la documentación del sitio de restauración. In Proceedings of the 2nd CIM, Santiago de Cuba, Cuba, 16-19 May 2017; pp. 1-4.

5. De Filippi, F. L'Ambiente Costruito Nella Cultura Islamica; Politecnico di Torino: Turin, Italy, 2002.

6. Dabdoub Nasser, C.; Hifẓ al-Turāth al-Thaqāfī, M. Anatreh Quarter: An Urban and Architectural Study of a Bethlehem Quarter; Centre for Cultural Heritage Preservation: Bethlehem, Palestine, 2005.

7. Palazzo, E. Rehabilitation Planning in the Historical Towns of the Occupied Palestinian Territory; Esempi di Architettura: Padova, Italy, 2009.

8. Parrinello, S. Il complesso di al-Nabi Musa in Palestina. Documentazione e analisi dell'oasi edificata. Disegnare Idee Immagin. 2017, 5, 68-79.

9. Parrinello, S. A Development Project for the United Nations. The Digital Survey for the Planning of East Jerusalem. In Putting Tradition into Practice: Heritage, Place and Design, Proceedings of the 5th INTBAU, Milan, Italy, 5-6 July 2017; Amoruso, G., Ed.; Intbau: Cham, Switzerland, 2017; pp. 551-559.

10. Picchio, F. Metodologie di rilievo integrato per indagini diagnostiche non invasive: La documentazione della Moschea Bianca di Al-Jazzar a San Giovanni d'Acri, Israele. Restauro Archeol. 2017, 26, 90-105.

11. Maniscalco, F. Tutela, Conservazione e Valorizzazione del Patrimonio Culturale Della Palestina; Massa Editore: Naples, Italy, 2005.

(C) 2019 by the authors. Licensee MDPI, Basel, Switzerland. This article is an open access article distributed under the terms and conditions of the Creative Commons Attribution (CC BY) license (http:/ / creativecommons.org/licenses/by/4.0/). 